OPEN ACCESS

Edited by:

Mohamed Fawzy Ramadan, Umm al-Qura University, Saudi Arabia

Reviewed by:

Myra O. Villareal,

University of Tsukuba, Japan

Dominique Guillaume,

Université de Reims

Champagne-Ardenne, France

Maria Desamparados Moya,

University of Castilla La

Mancha, Spain

Omer Alsawmahi,

King Saud University, Saudi Arabia

*Correspondence:

Said Gharby

s.gharby@uiz.ac.ma

Zoubida Charrouf

z.charrouf@yahoo.fr

Specialty section

This article was submitted to Nutrition and Food Science

Technology,

a section of the journal

Frontiers in Nutrition

Received: 29 October 2021 Accepted: 15 December 2021 Published: 03 February 2022

Citation:

Gharby S and Charrouf Z (2022)

Argan Oil: Chemical Composition, Extraction Process, and Quality Control. Front. Nutr. 8:804587. doi: 10.3389/fnut.2021.804587

\section{Argan Oil: Chemical Composition, Extraction Process, and Quality Control}

\author{
Said Gharby ${ }^{1 *}$ and Zoubida Charrouf ${ }^{2 *}$ \\ ${ }^{1}$ Laboratory Biotechnology, Materials and Environment, Department of Chemistry and Physics, Polydisciplinary Faculty of \\ Taroudant, Ibn Zohr University, Taroudant, Morocco, ${ }^{2}$ Laboratory of Plant Chemistry and Organic and Bioorganic Synthesis, \\ Department of Chemistry, Faculty of Sciences, Mohammed V University, Rabat, Morocco
}

Argan oil is considered a relatively international product exported from Morocco, although different companies in Europe and North America distribute argan oil around the globe. Argan oil is non-refined vegetable oil, of the more well-known "virgin oil" type, is produced from the argan tree [Argania spinosa (L.) Skeels]. The argan tree is deemed to be an important forest species from both social and economic standpoints. Argan oil has rapidly emerged as an important product able to bring more income to the local population. In addition, it also has important environmental implications, owing to its ability to stand against desert progression. Currently, argan oil is mainly produced by women's cooperatives in Morocco using a semi-industrial mechanical extraction process. This allows the production of high-quality argan oil. Depending on the method used to prepare argan kernels, two types of argan oil can be obtained: food or cosmetic grade. Cosmetic argan oil is prepared from unroasted kernels, whereas food argan oil is achieved by cold pressing kernels roasted for a few minutes. Previously, the same food argan oil was prepared exclusively by women according to a laborious ancestral process. Extraction technology has been evolved to obtain high-quality argan oil at a large scale. The extraction process and several accompanying parameters can influence the quality, stability, and purity of argan oil. In view of this, the present review discusses different aspects related to argan oil chemical composition along with its nutritional and cosmetic values. Similarly, it details different processes used to prepare argan oil, as well as its quality control, oxidative stability, and authenticity assessment.

Keywords: argan tree, argan oil, chemical composition, quality, oxidation, extraction

\section{ARGANERAIE AND ARGAN TREE}

Through the ages, the Amazigh population, the indigenous inhabitants of North Africa, has inhabited the arganeraie area of Morocco and has developed a lifestyle that depends on the argan tree. In Southwest Morocco, there was a noticeable degradation of argan forest from about 1.5 million ha to only an estimated 800,000 ha by the year $2000(1,2)$. The decline is anthropogenic but is also due to drought. As a consequence, Unesco declared the Moroccan argan forest a biosphere reserve in $1998(1,3)$. Since then, a comprehensive program aiming at saving the argan tree in a sustainable way has been underway in Morocco (4). Among its significant results is the scientific confirmation of traditional medicinal values virtues arising mostly from the main product, which 
is argan oil. Since then, argan oil is gaining significant value worldwide with increasing demand from year to year. In addition, in 2021, the United Nations Organization (UNO) recognized the importance of the argan tree by adopting May 10 as its international day.

Argan tree is an endemic plant found principally in Morocco (5), and it extends as far as the Hamada of Tindouf in Algeria (6). In addition, this tree has also been introduced as a cultivated species in the deserts of South Africa, Spain, Kuwait, Mexico, Tunisia, and Israel, among other countries of the world $(7,8)$.

Botanically, the argan tree is the only species of the Sapotaceae family to live above the tropics (9). It is a slow growing and thorny tree, well-adapted to the drylands of south-western Morocco (9). In its biotope, it plays an important ecological role including a deep root system that protects the soil from water and wind erosion, while its shade maintains soil fertility by preserving moisture $(10,11)$. In addition, the argan tree has multiple uses. Its leaves, fruits, and oil are a source of nutrients and bioactive compounds with nutritional, cosmetic, and economic benefits $(12,13)$. In this chapter, the chemical composition of argan oil along with its nutritional and cosmetic benefits will be discussed. We will detail different processes used to process argan oil, quality control, and assessment of oxidative stability.

\section{IMPORTANCE OF ARGAN OIL AS A FOOD AND COSMETIC PRODUCT}

It is widely evidenced that argan oil is an important food. It is prepared from roasted argan kernels, whose pressing can be performed using traditional and modern techniques (14-16). In both cases, the obtained argan oil has a golden color and a unique hazelnut taste (17). Food argan oil is sweet with a nutty flavor and it is known as one of the most nutritional oils in the world. This explains the consumer demand as well as the incorporation of argan oil into other several varieties of foods. Traditionally, argan oil used as a food is eaten with bread. In addition, it makes a great finishing flavor when drizzled over grilled salads, fish, tajin, and couscous. Moreover, food argan oil is also the main ingredient in Amlou, a paste similar to peanut butter obtained by grinding roasted almonds with honey and argan oil (Guillaume and Charrouf, 2013). A few years ago, argan oil became highly valued by major chefs in Europe. Food argan is the main source of fat used for food preparation in the Amazigh diet and, therefore, it is deemed to be symbolic of this cultural continuity (18-20).

Several scientific studies devoted to the development of argan oil for over 30 years have shown various promising nutritional characteristics of this product in human health (21).

There are two kinds of argan oils in the market, namely, food argan oil and beauty (cosmetic) use (name INCI: Argania spinosa kernel oil) (21). This is a cold pressed oil, however, it is obtained from unroasted argan kernels $(15,22)$. Cosmetic argan oil is intended to be applied directly to the skin or hair, or to be an ingredient in other cosmetic preparations $(21,23,24)$. Traditionally, cosmetic argan oil has been claimed to cure all kinds of skin anomalies with particular effectiveness

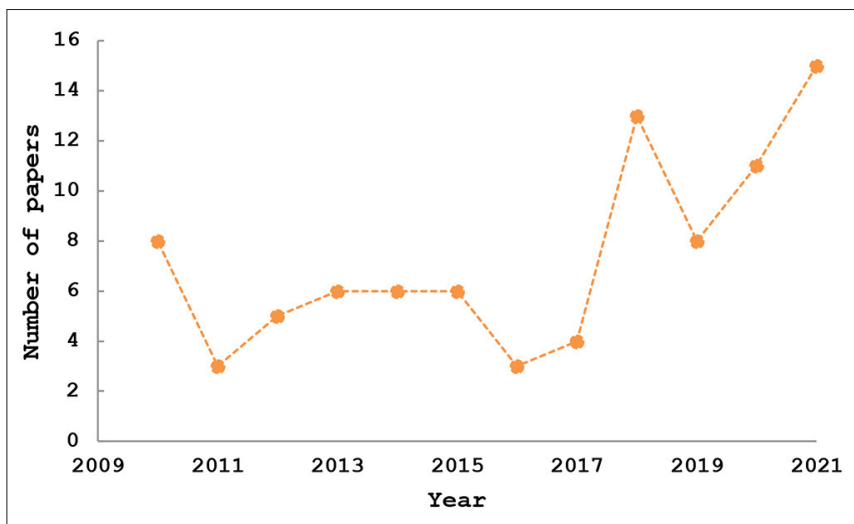

FIGURE 1 | Publication trends of argan oil composition (Based on data retrieved from Scopus database). Copyright (C) 2022 Elsevier B.V. All rights

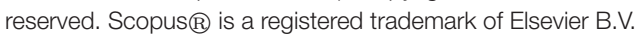

for juvenile acne and chickenpox. Additionally, it is also claimed to reduce the formation of wrinkles. Argan oil is generally used in cosmetology as a moisturizer as well as to cure devitalized skin. Added to shampoos, the oil penetrates the hair axis and damaged hair follicles, giving hair a fuller and shinier look. All these skin healing properties justify the wide use of argan oil in dermatological and cosmetic formulations (25).

Nutritional and cosmetic properties of either argan oil devoted to direct consumption or cosmetic end uses are the result of its unique chemical composition. Argan oil is rich in unsaturated fatty acid and bioactive molecules, such as polyphenols, tocopherols, squalene, xanthophyll, CoQ10, and sterols $(7,26)$.

\section{ARGAN OIL COMPOSITION}

A complete and updated analysis of the composition of olive oil reported in the literature is presented in Figure 1. In fact, on November 27, 2021, the Scopus database was chosen for the search. The search string: ("argan oil"” AND "composition*”) was utilized to extract bibliometric information from the Scopus online database.

The obtained results (Figure 1) showed that argan oil composition is well-documented.

Indeed, 86 publications were recovered through the literature search within the range of years from 2010 to 2021, 34 of them which represent about $40 \%$ are published in the interval of years from 2015 to 2021.

\section{Physicochemical Parameters}

Parameters systematically used to measure physicochemical properties of argan oil include density, refractive index, iodine value, saponification value, and unsaponifiable matter. In vegetable oils including argan oil, the density and refraction index depend on the temperature (27). Table 1 summarizes the ranges of the main physicochemical parameters of argan oil. The refractive index at $20^{\circ} \mathrm{C}$ varies from 1.463 to 1.472 . At 
TABLE 1 | Physicochemical parameters of cosmetic and edible argan oil.

\begin{tabular}{lc}
\hline Physicochemical properties & Norm (28) \\
\hline Density $\left(20^{\circ} \mathrm{C}\right)$ & $0.906-0.919$ \\
Refraction index $\left(20^{\circ} \mathrm{C}\right)$ & $1.463-1.472$ \\
Saponification value $(\mathrm{mgKOH} / \mathrm{g})$ & $189.0-199.1$ \\
lodine value $\left[\mathrm{g}\left(\mathrm{I}_{2}\right) / 100 \mathrm{~g}\right]$ & $91.0-110.0$ \\
Unsaponifiable $(\mathrm{g} / 100 \mathrm{~g})$ & $\leq 1.1$ \\
\hline
\end{tabular}

the same temperature, its density relative to water is between 0.906 and 0.919 (28). The iodine value is a measure of the total number of double bonds present in the oil sample (29). Argan oil shows an iodine value ranging from 91 to $110 \mathrm{mg} / 100 \mathrm{~g}(28,30)$ (Table 1). This value is lower than that of sunflower oil $\left(130 \mathrm{~g} \mathrm{I}_{2} / 100 \mathrm{~g}\right)$ and soybean seed oil [134.5 $\left.\mathrm{g}\left(\mathrm{I}_{2}\right) / 100 \mathrm{~g}\right]$ but higher than that of olive oil $[75-94 \mathrm{~g}$ $\left.\left(\mathrm{I}_{2}\right) / 100 \mathrm{~g}\right](31,32)$. High iodine-value is correlated to a greater number of double bonds and reduced oxidative stability (32, 33). The saponification value is a measure of the average fatty acid chain lengths. The oil with shorter fatty acid has a higher saponification value. The saponification value of argan oil according to SNIMA norm is $189.0-199.1 \mathrm{mg}(\mathrm{KOH}) / \mathrm{g}$. It is noteworthy that a high saponification value indicates high triglycerides content. This aspect is very appreciated in cosmetology (32).

\section{Fatty Acid, Phytosterol, Tocopherol, and Volatile Compounds Composition}

The most important components in vegetable oils are fatty acids (Table 2). It is noteworthy that the characteristics, stability, and nutritive value of a given vegetable oil depend strongly upon the fatty acid composition $(34,35)$. In this regard, argan oil is composed of about $80 \%$ of unsaturated fatty acids and only approximately around $19 \mathrm{~g} / 100 \mathrm{~g}$ saturated fatty acids (Figure 1). The nutritional benefits of unsaturated fatty acids are widely documented $(36,37)$. Oleic acid $(43-49 \mathrm{~g} / 100 \mathrm{~g})$ and linoleic acid (29-37 g/100 g) are the major unsaturated fatty acids found in argan oil $(4,20,38)$. Linolenic acid, a very oxidizable molecule, is also present in very low concentrations usually $<0.3 \mathrm{~g} / 100 \mathrm{~g}$ (39). This small content of linolenic acid can be used to detect the adulteration of argan oil with other vegetable oils rich in linolenic acids, such as soybean and rapeseed oils (39). Argan oil also contains two primary saturated fatty acids namely stearic acid (3.14-3.28 g/100 g) and palmitic acid $(11.70-11.75 \mathrm{~g} / 100 \mathrm{~g})(1,40)$. Other fatty acids, such as myristic acid (C14:0), palmitoleic acid (C16:1), arachidic acid (C20:0), and behenic acid (C22:0) are found only in relatively lower quantities (41).

Sterols, otherwise referred to as phytosterols, are the second class of compounds found in argan oil after fatty acids (Figure 2). The content of phytosterols in argan oil may be up to $220 \mathrm{mg} / 100 \mathrm{~g}(28,30)$. They are usually used to prove authenticity since they can be considered as a fingerprint of argan oil (42). In addition, sterols are important
TABLE 2 | The fatty acids, phytosterols, and tocopherols composition of argan oil.

\begin{tabular}{|c|c|c|c|}
\hline Fatty acid $(\mathrm{g} / 100 \mathrm{~g})$ & Norm (28) & Tocopherol & Norm (28) \\
\hline Myristic acid (C14:0) & $\leq 0.2$ & $\alpha$-Tocopherol (g/100 g) & $2.4-6.5$ \\
\hline Palmitic acid (C16:0) & $11.5-15$ & $\beta$-Tocopherol (g/100 g) & $0.1-0.3$ \\
\hline Stearic acid (C18:0) & $4.3-7.2$ & $\gamma$-Tocopherol (g/100 g) & $81-92$ \\
\hline Arachidic acid (C2O:0) & $\leq 0.5$ & $\delta$-Tocopherol (g/100 g) & $6.2-12.8$ \\
\hline Behenic acid (C22:0) & $\leq 0.2$ & Total tocopherol (mg/100 g) & $60-90$ \\
\hline$\Sigma$ SFA & $15.8-23.1$ & Phytosterol (g/100 g) & Norm \\
\hline Palmitoleic acid (C16:1) & $\leq 0.2$ & Cholesterol & $\leq 0.4 \%$ \\
\hline Oleic acid (C18:1) & $43.0-49.1$ & Campesterol & $\leq 0.4 \%$ \\
\hline Eicosenoic acid (C20:1) & $\leq 0.5$ & $\Delta$-7-Avenasterol & $4.0-7.0$ \\
\hline$\Sigma$ MUFA & $43-49.8$ & Schotenol & $44.0-49.0$ \\
\hline Linoleic acid (C18:2) & $29.3-36.0$ & Stigmasta-8-22-dièn-3 $\beta$-ol & $3.2-5.7$ \\
\hline Linolenic acid (C18:3) & $\leq 0.3$ & Spinasterol & $34.0-44.0$ \\
\hline$\Sigma$ PUFA & $29-36.3$ & Total sterol $(\mathrm{mg} / 100 \mathrm{~g})$ & $\leq 220$ \\
\hline
\end{tabular}

SFA, saturated fatty acids, MUFA, monounsaturated fatty acids, PUFA, polyunsaturated fatty acids.

molecules endowed with potent biological properties and their determination is of major interest due to their antioxidant activity and beneficial impact on health (43-45). Spinasterol (34.0-44 g/100 g) and Schotenol (44.0-49 g/100 g) are the major argan oil sterols followed by $\Delta 7$-Avenasterol (4.0-7.0 g/100 g) and stigmasta-8-22-dièn-3 $\beta$-ol (3.2-5.7 g/100 g) (46) (Table 2; Figure 3). Campesterol is found at a very low level but this is interesting for argan oil authenticity assessment $(47,48)$. This is also rich in squalene, with content much higher than that found in sunflower oil, but is lower than that of the olive oil $(49,50)$.

In addition to the fatty acid composition and phytosterol profile, the composition of tocopherol compounds is an important characteristic of argan oil (51). The tocopherol composition is closely related to stability, cosmetic, and nutritional proprieties $(39,52)$ and can be used for detecting adulterations in argan oil (53). Argan oil is very rich in tocopherols $(15,51)$. The total tocopherol content is between 60 and $90 \mathrm{mg} / 100 \mathrm{~g}$. $\gamma$-tocopherol is the main tocopherol found in argan oil (between 81 and $92 \mathrm{~g} / 100 \mathrm{~g}$ ), followed by $\delta$-tocopherol (6.2-12.8 g/100 g), $\alpha$-tocopherol (2.4-6.5 g/100g), and $\beta$ tocopherol $(0.1-0.3 \mathrm{~g} / 100 \mathrm{~g})(28,46)$. In addition, it contains other bioactive compounds of important antioxidant power, such as polyphenols (54), coenzyme Q10, and melatonin (26).

A large number of different classes of chemical compounds, such as hydrocarbons, ketones, furans, and aldehydes, participate in the final aroma of argan oil (55). The volatile fraction of virgin argan oils has been reported to have approximately eight major families: acids, alcohols, aldehydes, ketones, esters, terpenes, $\mathrm{N}$-heterocycles, and furans (55). However, argan oil obtained from goat-peeled fruit possesses additional volatile compounds (56). The volatile compounds of cold pressed argan oil are strongly dependent on the roasting process that is particularly applied to food-grade argan oil. In fact, during the process of roasting, an aroma is developed, which is preserved in the oil during the process of extraction. The principal ways of 

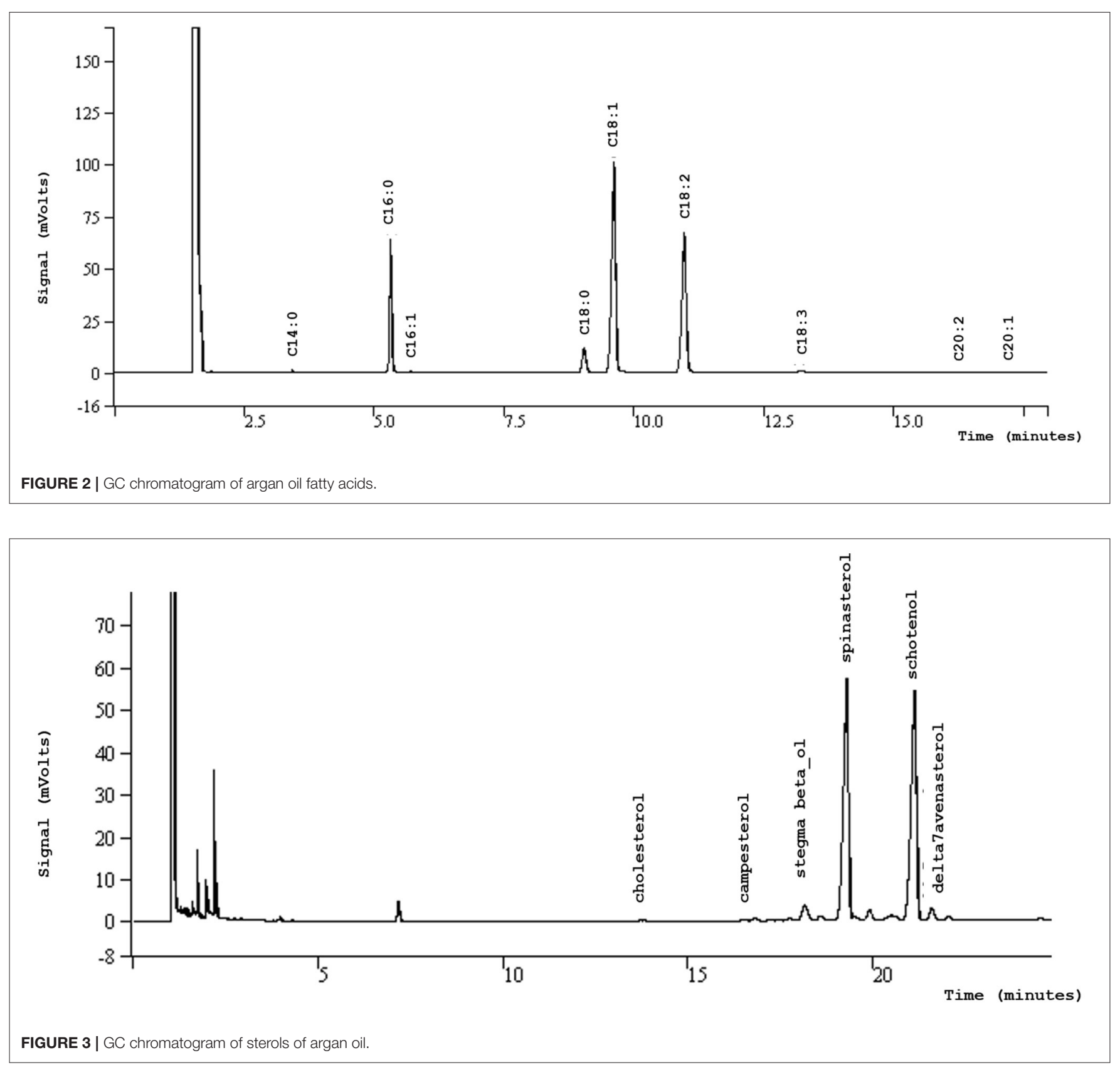

formation of the flavor during the roasting of argan kernels are the oil oxidation and the Maillard reaction (19). Indeed, the volatile profile of the oil extracted from unroasted kernels is dominated by the presence of oil oxidation products, such as hexanal, pentanal, and 2-pentyl-furan, and by N-heterocycles, such as 1-methyl-1-pyrrole, 2,6-dimethyl pyrazine, and other pyrazines, alcohols (1-hexanol, 2,3-butanediol, 2-methyl-1propanol), ketones (acetoin), and acetic acid $(55,57)$. However, the volatile content of food grade oil is significantly marked by an increased level of products of the Maillard reaction, such as the Strecker aldehydes 2-methyl propanal, 2- and 3-methyl butanal, and the $\mathrm{N}$-heterocycles 1-methyl-1-pyrrole, methyl pyrazine, 2,6-dimethyl pyrazine, 2-ethyl-5-methyl pyrazine, trimethyl pyrazine, 3-ethyl-2,5-dimethyl pyrazine, and furfural. Matthäus et al. (19) have previously demonstrated that hexanal can be identified as an oxidation indicator in both untreated and roasted argan oils. Furthermore, El Monfalouti et al. (55) investigated the impact of roasting time on the concentration of volatiles in the extracted oil, emphasizing that almost all roastingrelated volatiles commenced being generated after $15-25 \mathrm{~min}$ of roasting. In another study, Gracka et al. (57) characterized the major odors, using gas chromatography olfactometric analysis, and the sensory properties of raw and roasted kernel oils. The two oils showed increased oily and rancid olfactive notes at 
the end of an accelerated storage experiment, whereas certain aldehydes were recognized as potential indicators of oxidation during storage (57).

\section{ARGAN OIL EXTRACTION}

For a long time ago, argan oil has been prepared exclusively by Amazigh women according to a laborious ancestral traditional extraction method $(40,58)$. The traditional process of extraction, transmitted from mother to daughter, includes seven steps (Figure 4): (1) fruit picking: from May to August, ripe fruits are collected from the argan forest. The fruits are collected manually and sun-dried for a few weeks. Harhar et al. (59) showed that a 2 -week fruit drying time is optimum to prepare the high quality of argan oil. (2) Fruit peeling: following the drying period, their dried peel is manually removed, resulting in "argan nuts"; (3) nut cracking: the argan nuts are broken open, kernels selected, and collected. (4) Kernel roasting: the kernels are then gently roasted in clay plates for a few minutes. The amount of time depends on each woman who evaluates it based on the color and the odor of the kernels. An average of $30-40 \mathrm{~min}$ is necessary to roast $1 \mathrm{~kg}$ of kernels. Roasting time strongly influences the final oil taste. A burning taste results from overheating of the material and needs to be avoided. This step is necessary to get limpid oil having reproducible color and odor characteristics. (5) The fifth step consists of kernel grinding: the roasted kernels are crushed using a millstone. This artisanal process is composed of two stones: a bedstone and a cone-shaped rotating piece largely pierced in its center through which the kernels are introduced. (6) In the sixth step, i.e., malaxing: the resultant oily dough is hand-malaxed for several minutes, while small quantities of water are added. As the dough slowly gets solid, it releases an emulsion from which argan oil is decanted. (7) Oil extraction: the final stage is traditional oil extraction. This process is very laborious. Indeed, for a single person, $24 \mathrm{~h}$ of work is needed to extract about $1 \mathrm{~L}$ of oil from $50 \mathrm{~kg}$ of fruits. The solid residue remaining after the maximum quantity of oil has been collected may still contain up to $25 \%$ of oil. In addition, traditional extraction is frequently achieved in unsatisfactory sanitary conditions, particularly, in terms of bacteriological safety, traceability, and oxidative stability (17). As a solution, a change was made to increase argan oil quality and traceability by improving its extraction technology.

The introduction of a mechanical technique by several industrial units and women's cooperatives improved not only the quality certified of oil but also its yield (41). In fact, the oil preparation process was only slightly modified: the fruits are peeled mechanically, and the oil is obtained by press extraction. In the advancement of this process, the use of water for extraction has been eliminated and the roasting step has been improved. This process has two advantages. First, argan oil can join olive oil as a "virgin extra argan oil" and, second, the new technology preserves all the known benefits of argan oil. As of this writing, argan oil is still being prepared in some sectors of Morocco using mechanical presses, however, in some industrial units and cooperatives, highly efficient, hydraulic presses have replaced endless crews (4). With this process (mechanical or hydraulic process), two types of oil can be obtained: food or cosmetic grade (48). Food argan oil is achieved by cold pressing kernels roasted for a few minutes, whereas cosmetic oil is prepared from unroasted kernels $(14,58)$. Food argan oil extraction follows six steps: fruit collection, sun-drying, dehulling, nut breaking (or kernel collection), kernel roasting, and cold-pressing. Oil decantation and filtration are also added to remove large amounts of waxes and gums. Skipping the roasting step leads to the production of cosmetic oil. Food argan oil is copper-colored whereas cosmetic argan oil is gold-colored. Each processing step dramatically influences the resulting oil in terms of quantity and quality. The importance of the extraction method on the oil quality is already particularly well-documented $(19,41)$. The effects of fruit quality and drying-time on argan oil quality have also been evaluated $(19,22,41,59)$. Concerning the roasting stage, the impact of its duration and the resulting volatile compounds production are well-documented (22). Besides, food argan has a hazelnut-like taste, mostly resulting from the presence of volatile compounds formed during kernel roasting. Volatile compounds, produced via oxidation, and/or Maillard reaction, actively participate in the preservation of food oil $(19,60,61)$.

\section{QUALITY CONTROL OF ARGAN OIL}

Argan oil is subject to numerous analytical and sensory controls to assess its overall quality. These analyses specify the freshness of the oil concerning hydrolytic and oxidative alterations to ensure the conformity of products to their labels. For example, "extra virgin argan oil" by simple analyses [free fatty acids, peroxide value, and specific extinction (E270 and E232)] and/or purity blending with other oils and contaminants. These criteria require detailed analyses (triglycerides contents, fatty acids, sterols, tocopherols, etc.). In addition, organoleptic characteristics (taste, odor, and color) also need to be taken into consideration.

As with other vegetable oils, the oxidation of argan oil leads to natural phenomena alteration $(60,62)$. This can be controlled from fruit harvest until the storage of the oil. Because of the possibility of oxidation, physicochemical criteria, such as acidity, peroxide value, and extinction specific at wavelength 270 (E270), have been selected as the backbone of argan oil quality determination by the Moroccan Standard (08.5.090). Acidity of argan oil is classified in four grades: extra-virgin (acidity < $0.8 \mathrm{~g} / 100 \mathrm{~g})$, fine-virgin $(0.8<$ Acidity $<1.5 \mathrm{~g} / 100 \mathrm{~g})$, ordinary virgin $1.5<$ Acidity $<2.5 \mathrm{~g} / 100 \mathrm{~g}$ ), and lampante virgin argan oil (acidity $>2.5)$ (28).

The variability of the extra-virgin argan oil acid value as a function of various parameters has been studied $(41,60)$. In addition, seed origin and the technology associated with extraction are parameters possibly modifying the argan oil acidity $(41,60,63)$. The oxidative state of oil can be examined from peroxide value and specific extinction coefficient (E232), which indicates the presence of primary oxidation products $(20,64)$. The peroxide value of extra-virgin argan oil must be lower than $15 \mathrm{mEq} \mathrm{O}_{2} / \mathrm{kg}$ (65) and specific extinction E232 is not yet been set in The Moroccan standard (28). 


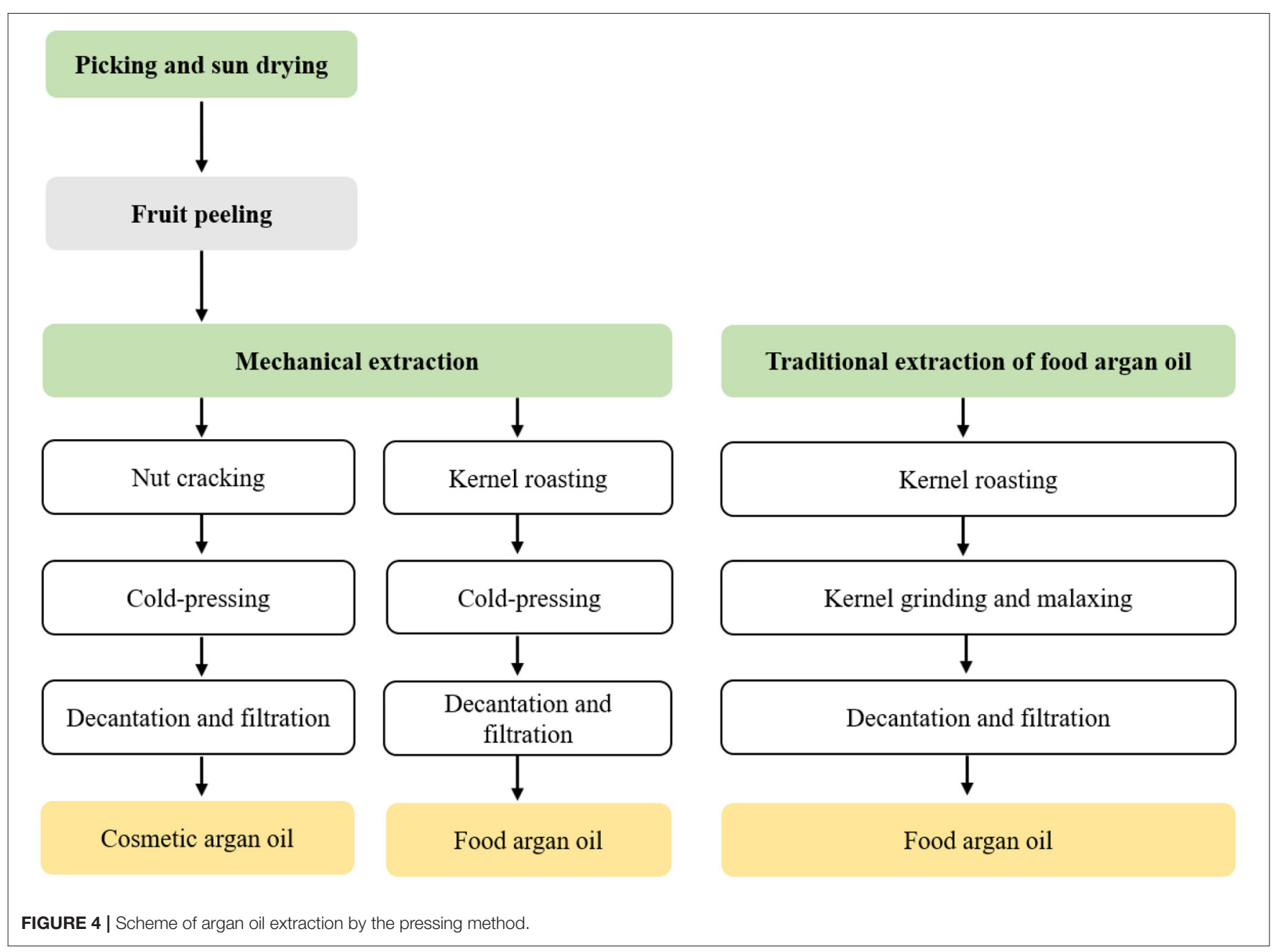

Nevertheless, Kharbach et al. (66) have considered that the specific extinction E232 should not exceed 2.52 for extra virgin argan oil. The other two important indices used to evaluate the secondary oxidation products are p-anisidine value and specific extinction E270 (20, 64). The Moroccan Standard has fixed 0.25 as a limit value for extra virgin argan oil. In addition to the oxidation and acidity concerns, the quantification of major compounds, such as fatty acids, and minor compounds, such as sterols, polyphenols, tocopherols, and minerals elements, are also important considerations for the purity of argan oil.

Finally, identifying contaminants is one of the multiple checks that must be conducted on oils. Vegetable oils have fixed limit values for heavy metals, some mycotoxins, aromatic hydrocarbons polycyclics (PAHs), phthalates, and pesticides. Although the physicochemical characterization of argan oil is an essential step, it is not sufficient (60). To satisfy the consumer, organoleptic characteristics (taste, smell, color, etc.) must be taken into consideration. This is particularly true for food argan oil. An organoleptic analysis is an essential criterion for successful food marketing and an integral part of evaluating food argan oil.

\section{ARGAN OIL OXIDATIVE STABILITY}

Oil oxidation is a key factor responsible for oil quality during storage time. The loss of oil nutritional quality and the rise of undesirable off-flavors. This makes foods containing lipids less acceptable to consumers. Moreover, during the oxidation process, some toxic compounds, such as reactive carbonyl compounds can generate advanced lipid peroxidation end products which are potentially harmful to human health (67). Argan oil oxidation depends on oil fatty acid composition, the presence of endogenous antioxidants, and external factors, such as high temperatures and high oxygen availability (62). It is an undesirable set of chemical reactions that can be perceived, at the initial stage, as a deterioration of both taste and smell (rancidity). The oxidation of oil begins with radical reactions on unsaturated fatty acids and involves multiple stages, resulting in various decomposition products. Most of them are peroxides (primary oxidation products), while alcohols and volatile compounds (aldehydes and ketones) constitute secondary oxidation products (29).

In this context, argan oil oxidative stability is extensively documented $(19,34,51,53,60,68,69)$. Several techniques and 


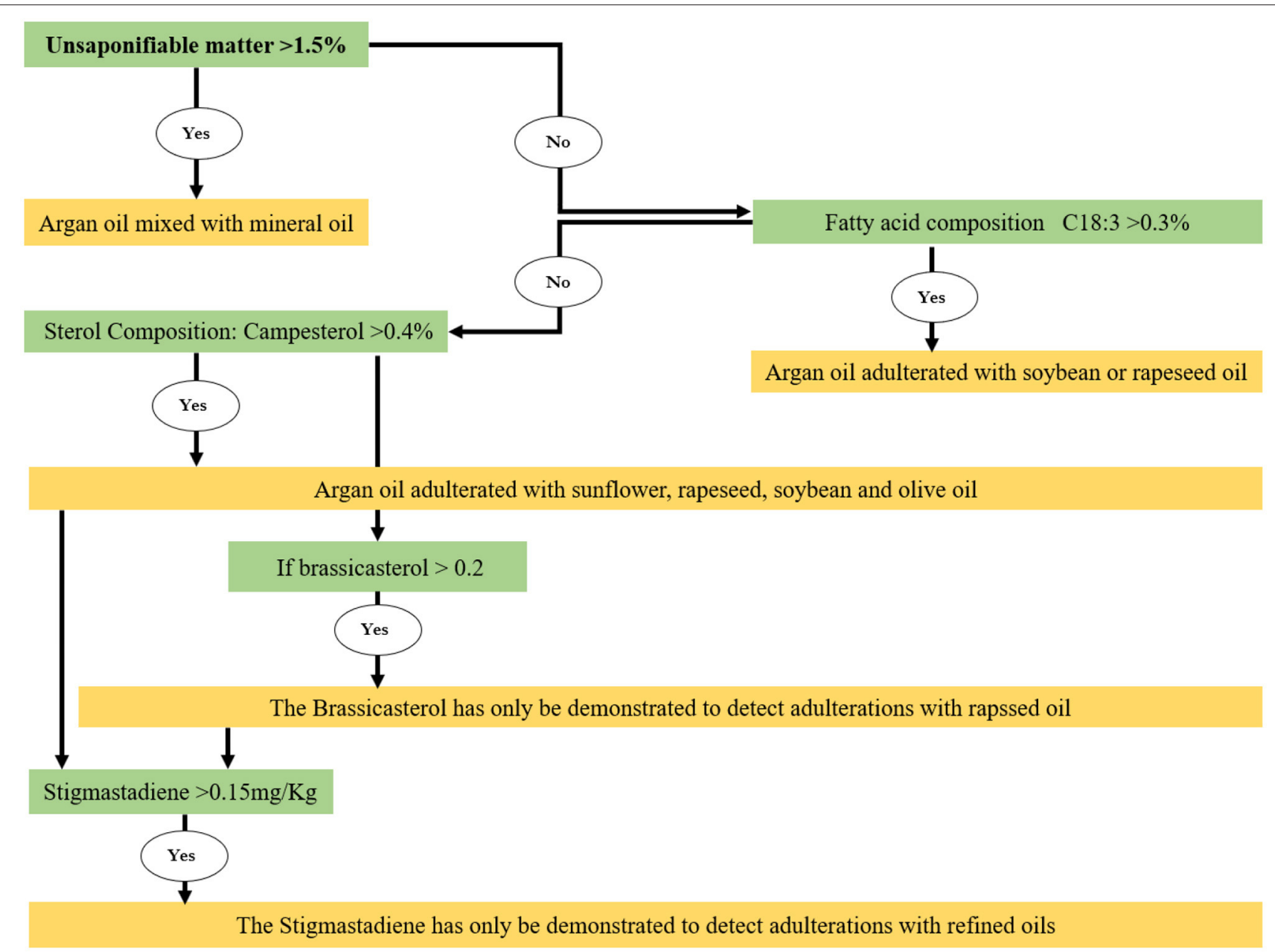

FIGURE 5 | Scheme of the main analytical methods for determination of argan oil adulteration by vegetable oils.

studies have been used to estimate the shelf-life of argan oil, such as Rancimat induction time, under accelerated conditions at $60^{\circ} \mathrm{C}$ as well as estimating its shelf-life for 2 years at $25^{\circ} \mathrm{C}$ (protected or exposed to sunlight) $(60,61,70)$. Despite its high unsaturated fatty acid content, food argan oil prepared by press cold extraction has been proven to display a very good shelflife and high preservation characteristics (60). For instance, at $110^{\circ} \mathrm{C}$, food argan oil prepared by press cold extraction present an average Rancimat induction period of $31 \mathrm{~h}$, whereas it is only $13 \mathrm{~h}$ for cosmetic argan oil. At high storage temperature $\left(60^{\circ} \mathrm{C}\right)$ for 35 days, argan oil from roasted kernels prepared by press cold extraction shows high oxidative stability (19). Previous works $(60,69,70)$ have estimated argan oil shelf-life for a duration of 2 years at $25^{\circ} \mathrm{C}$ in protected conditions or exposed to sunlight. The obtained results indicated that the food argan oil prepared by press cold extraction, for a storage period of 2 years showed that the best stability is obtained in the shelter of light and at $25^{\circ} \mathrm{C}$. However, under the same conditions, cosmetic argan oil can only be preserved for 1 year $(46,69)$. Kharbach et al. (71) have studied the shelf-life of food and cosmetic argan oils based on chemical properties or Fourier Transform Infrared (FTIR) fingerprints and chemometrics. Since cosmetic and food argan oil differs only by kernels roasting and the life span of food argan oil is longer than that of cosmetic oil. More precisely, the moisture content in the food argan oil is lower, its phospholipid content (70) and the formation of antioxidant active compounds during the roasting process (e.g., could be responsible for this stability) is higher.

\section{DETERMINATION OF VIRGIN ARGAN OIL ADULTERATION}

Detection of food adulteration is of great importance to ensure product quality and consumer protection. The multistage extraction process and the superior value over other oils explain the high price of argan oil. For these reasons, this oil has been called "the most expensive vegetable oil in the world." Unfortunately, this position increases the risk of adulteration using other lower-cost oil. To reduce this risk, several official analytical methods have been developed and 
proposed to detect adulteration in both cosmetic and food argan oil (Figure 5). The different methods of dosage are reviewed: unsaponifiable matter fatty acid, sterol, tocopherol, triglycerides, trace elements, and polyphenol spectrometric. These methods are widely applied to quality research on vegetable oils, such as olive oil. Adulteration of argan oil with cheaper oils rich in linolenic acid (rapeseed and soybean oils) can be easily and quickly detected by the determination of the fatty acid composition using gas chromatographic since linoleic acid represents only $<0.3 \%$ in argan oil. Indeed, Miklavcic et al. (72) have investigated the authenticity of cosmetic argan oil using fatty acid composition. With the same technique, other authors reported that adulterations of this oil could be detected by the analysis of campesterol of phytosterol composition. Indeed, campesterol, a sterol found in vegetable oils, is present only in traces $(0.4 \%)$ in the total sterols content of argan oil. This low level of campesterol in argan oil can be used to detect adulteration of argan oil with other oils rich in campesterol, such as olive, soybean, rapeseed, and sunflower oils (42). This analysis determines argan oil purity up to $98 \%$ (4). In addition, quantification of tocopherols $(53,73)$, hydrocarbons (74), ferulic acid (75), triglyceride (76), and stigmasta-3,5-diene has been reported. Dosage of trace elements is suggested as another analytical method for the assessment of argan oil adulteration (13, $14,77)$. Other authors have used the content of unsaponifiable matter to detect the adulteration of argan oil by mineral

\section{REFERENCES}

1. Charrouf Z, Harhar H, Gharby S, Guillaume D. Enhancing the Value of Argan Oil Is the Best Mean to Sustain the Argan Grove Economy and Biodiversity, so Far. Oil Crops and Lipids (2008).

2. Harhar H, Gharby S, Kartah B, El Monfalouti H, Pioch D, Guillaume D, et al. Effect of harvest date of Argania spinosa fruits on argan oil quality. Indust Crops Prod. (2014) 56:156-9. doi: 10.1016/j.indcrop.2014.01.046

3. Kirchhoff M, Romes T, Marzolff I, Seeger M, Aït Hssaine A, Ries JB. Spatial distribution of argan tree influence on soil properties in southern Morocco. Soil. (2021) 7:511-24. doi: 10.5194/soil-7-511-2021

4. Charrouf $Z$, Guillaume D. The argan oil project: going from utopia to reality in 20 years. OCL. (2018) 25:1-5. doi: 10.1051/ocl/2018006

5. Moutik S, Benali A, Bendaou M, Maadoudi EH, Kabbour MR, El Housni A, et al. The effect of using diet supplementation based on argane (Argania spinosa) on fattening performance, carcass characteristics and fatty acid composition of lambs. Heliyon. (2021) 7. doi: 10.1016/j.heliyon.2021. e05942

6. Mechqoq H, El Yaagoubi M, El Hamdaoui A, Momchilova S, da Silva Almeida JR, et al. Ethnobotany, phytochemistry and biological properties of argan tree (Argania spinosa (L) Skeels) (Sapotaceae) - a Review. J Ethnopharm. (2021) 281:114528. doi: 10.1016/j.jep.2021.114528

7. Khallouki F, Voggel J, Breuer A, Ulrich C, Owen R, Klika K. Comparison of the major polyphenols in mature argan fruits from two regions of Morocco. Food Chem. (2017) 221:1034-40. doi: 10.1016/j.foodchem.2016. 11.058

8. Koufan M, Belkoura I, Mazri MA, Amarraque A, Essatte A, Elhorri H, et al. Determination of antioxidant activity, total phenolics and fatty acids in essential oils and other extracts from callus culture, seeds and leaves of Argania spinosa (L) skeels. Plant Cell Tiss Organ Cult. (2020) 141:21727. doi: 10.1007/s11240-020-01782-w

9. Guillaume D, Charrouf Z. Argan oil for nutritional and skin care applications. HœPC Today. (2013) 8:28-30. oil (4). Recently, El Orche (78) has used three fingerprint analytical approaches based on spectroscopic sensors and chemometrics for the detection and quantification of argan oil adulteration (78).

\section{CONCLUSION}

In this chapter, various aspects related to chemistry, different processes used for argan oil preparation, quality control, oxidative stability, and authenticity assessment of argan oil are summarized in light of published literature. A few years ago, both types of argan oil (cosmetic or food) have found their place in the highly competitive international oil market. This is the result of its unique chemical composition associated with its nutritional and cosmetic properties as well as with scientific studies validating its claimed or empirically observed properties. With such an approach, the commercial success of argan oil has been achieved globally. This success is a very positive sign for the preservation of argan oil.

\section{AUTHOR CONTRIBUTIONS}

SG: resources, data acquisition, methodology, and writingreview and editing. ZC: supervision and writing-review and editing. Both authors contributed to the article and approved the submitted version.
10. Ganoudi M, Calonne-Salmon M, Ibriz M, Declerck S. In vitro mycorrhization of Argania spinosa L. using germinated seeds. Symbiosis. (2021) 85:5768. doi: 10.1007/s13199-021-00790-4

11. Charrouf Z, Guillaume D. Sustainable development in northern Africa: the argan forest case. Sustainability. (2009) 1:1012-22. doi: 10.3390/su1041012

12. Chakhchar A, Lamaoui M, El Kharrassi Y, Bourhim T, Filali-Maltouf A, El Modafar C. A review on the root system of Argania spinosa. Curr Agr Res J. (2020) 8:1. doi: 10.12944/CARJ.8.1.03

13. Ibourki, M., Gharby, S., Guillaume, D., Laknifli, A., El Hammadi, A., and Charrouf, Z. (2021). Profiling of Mineral Elements and Heavy Metals in Argan Leaves and Fruit By-Products Using Inductively Coupled Plasma Optical Emission Spectrometry and Atomic Absorption Spectrometry. Chem. Data Collec. 35:100772. doi: 10.1016/j.cdc.2021.100772

14. Mohammed FA. E., Bchitou, R., Bouhaouss, A., Gharby, S., Harhar, H., D., et al. Can the Dietary Element Content of Virgin Argan Oils Really Be Used for Adulteration Detection? Food Chem. (2013) 136:1058. doi: 10.1016/j.foodchem.2012.07.098

15. Zaaboul F, Raza H, Lazraq A, Deng B, Cao C, Liu Y. F. Chemical composition, physical properties, and the oxidative stability of oil bodies extracted from Argania spinosa. J Amer Oil Chem Soc. (2018) 95:48595. doi: 10.1002/aocs.12053

16. Zeghlouli J, Guendouz A, Duchez D, El Modafar C, Michaud P, Delattre C. Valorization of co-products generated by argan oil extraction process: application to biodiesel production. Biofuels. (2021) 1:7. doi: 10.1080/17597269.2021.1941573

17. Charrouf Z, Guillaume D. Argan oil, the 35-years-of-research product. Eur. J. Lip. Sci. Technol. (2014) 116:1316-21. doi: 10.1002/ejlt.201400261

18. Charrouf Z, Guillaume D. Should the amazigh diet (regular and moderate argan-oil consumption) have a beneficial impact on human health? Crit. Rev. Food Sci. Nutr. (2010) 50:473-4. doi: 10.1080/10408390802544520

19. Matthäus B, Guillaume D, Gharby S, Haddad A, Harhar H, Charrouf Z. Effect of processing on the quality of edible argan oil. Food Chem. (2010) 120:426-32. doi: 10.1016/j.foodchem.2009.10.023 
20. Harhar H, Gharby S, Guillaume D, Charrouf Z. Effect of argan kernel storage conditions on argan oil quality. Eur J Lip Sci Technol. (2010) 112:91520. doi: 10.1002/ejlt.200900269

21. Guillaume D, Charrouf Z. Argan oil and other argan products: use in dermocosmetology. Eur J Lip Sci Technol. (2011) 113:4038. doi: 10.1002/ejlt.201000417

22. Harhar H, Gharby S, Kartah B, El Monfalouti H, Guillaume D, Charrouf Z. Influence of argan kernel roasting-time on virgin argan oil composition and oxidative stability. Plant Foods Hum Nutr. (2011) 66:163-8. doi: 10.1007/s11130-011-0220-x

23. Manca ML, Manconi M, Meloni MC, Marongiu F, Allaw M, Usach I, et al. Nanotechnology for natural medicine: formulation of neem oil loaded phospholipid vesicles modified with argan oil as a strategy to protect the skin from oxidative stress and promote wound healing. Antioxidants. (2021) 10:670. doi: 10.3390/antiox10050670

24. Bejaoui M, Taarji N, Saito M, Nakajima M, Isoda H. Argan (Argania spinosa) press cake extract enhances cell proliferation and prevents oxidative stress and inflammation of human dermal papilla cells. J Dermat Sci. (2021) 103:3340. doi: 10.1016/j.jdermsci.2021.06.003

25. Tichota DM, Silva AC, Sousa Lobo JM, Amaral MH. Design, characterization, and clinical evaluation of argan oil nanostructured lipid carriers to improve skin hydration. Inter J Nanomed. (2014) 9:3855-64. doi: 10.2147/IJN. S64008

26. Venegas C, Cabrera-Vique C, García-Corzo L, Escames G, Acuña-Castroviejo D, López LC. Determination of coenzyme Q 10, coenzyme Q 9, and melatonin contents in virgin argan oils: comparison with other edible vegetable oils. J Agr Food Chem. (2011) 59:12102-8. doi: 10.1021/jf203428t

27. Kanda LRS, Yamamoto CI, Lopes AR, Voll FAP, Corazza ML, Wypych F. Density, refractive index and viscosity as content monitoring tool of acylglycerols and fatty acid methyl esters in the transesterification of soybean oil. Anal Meth. (2016) 8:5619-27. doi: 10.1039/C6AY00663A

28. SNIMA. Corps Gras d'origines Animale et Végétale :Huiles diargane. PNM 08.5.090 SNIMA (2003).

29. Gharby S, Harhar H, Matthäus B, Bouzoubaa Z, Charrouf Z. The chemical parameters and oxidative resistance to heat treatment of refined and extra virgin moroccan picholine olive oil. J Taibah Univer Sci. (2016) 10:1006. doi: 10.1016/j.jtusci.2015.05.004

30. Gharby S, Harhar H, El Monfalouti H, Kartah B, Maata N, Guillaume D, et al. Chemical and oxidative properties of olive and argan oils sold on the Moroccan market. A comparative study mediter. J Nutr and Metab. (2012) 5:31-8. doi: 10.1007/s12349-011-0076-5

31. COI/T 15/NC, $\mathrm{N}^{\circ}, 3 /$ Rév. Norme commerciale applicable aux huiles d'olive et aux huiles de grignons d'olive. Madrid: International Olive Council (2019).

32. Zine S, El Hadek M. Physicochemical characterization of opuntia ficus-indica seed oil from Morocco. Biosci Biotechnol Res Asia. (2013) 10. doi: $10.13005 / \mathrm{bbra} / 1099$

33. Gharby S, Harhar H, Bouzoubaa Z, Asdadi A, El Yadini A, Charrouf Z. Chemical characterization and oxidative stability of seeds and oil of sesame grown in Morocco. J Saudi Soc Agric Sci. (2017) 16:10511. doi: 10.1016/j.jssas.2015.03.004

34. Gharby S, Guillaume D, Nounah I, Harhar H, Hajib A, Matthäus B, et al. Shelf life of moroccan prickly pear (Opuntia Ficus-Indica) and argan (Argania spinosa) oils: a comparative study. Grasas Aceites. (2021) 72. doi: $10.3989 /$ gya.1147192

35. Nounah I, Gharby S, Hajib A, Harhar H, Matthäus B, Charrouf Z. Effect of seeds roasting time on physicochemical properties, oxidative stability, and antioxidant activity of cactus (Opuntia Ficus-Indica L.) seed oil. J Food Proc Preser. (2021) 49:e15747. doi: 10.1111/jfpp.15747

36. Lizard G, Filali-Zegzouti Y, El Midaoui A. Benefits of argan oil on human health-May 4-6 2017, errachidia, Morocco. Inter J Molec Sci. (2017) 18:1383. doi: 10.3390/ijms 18071383

37. Simões T, Ferreira J, Lemos MFL, Augusto A, Félix R, Silva SFJ, et al. Argan oil as a rich source of linoleic fatty acid for dietetic structured lipids production. Life. (2021) 11:1114. doi: 10.3390/life11111114

38. Elgadi S, Ouhammou A, Taous F, Zine H, Papazoglou EG, Elghali T, et al. Combination of stable isotopes and fatty acid composition for geographical origin discrimination of one argan oil vintage. Foods. (2021) 10:1274. doi: $10.3390 /$ foods 10061274
39. Gharby S, Ravi HK, Guillaume D, Abert Vian M, Chemat F, Charrouf Z. 2-methyloxolane as alternative solvent for lipid extraction and its effect on the cactus opuntia ficus-indica L. seed oil fractions. OCL. (2020) 27:7. doi: $10.1051 / \mathrm{ocl} / 2020021$

40. Charrouf Z, Guillaume D. Secondary metabolites from Argania spinosa (L.) Skeels. Phytochem Rev. (2002) 1:345-54. doi: 10.1023/A:1026030100167

41. Hilali M, Charrouf Z, Soulhi AEA, Hachimi L, Guillaume D. Influence of origin and extraction method on argan oil physico-chemical characteristics and composition. J Agr Food Chem. (2005) 53:2081-7. doi: 10.1021/jf04 $0290 \mathrm{t}$

42. Hilali M, Charrouf Z, Soulhi AEA, Hachimi L, Guillaume D. Detection of argan oil adulteration using quantitative campesterol GC-analysis. J Amer Oil Chem Soc. (2007) 84:761-4. doi: 10.1007/s11746-007-1084-y

43. Gharby S, Harhar H, Mamouni R, Matthaüs B, Ait Addi EH, Charrouf Z. Chemical characterization and kinetic parameter determination under rancimat test conditions of four monovarietal virgin olive oils grown in morocco. OCL. (2016) 23:8. doi: 10.1051/ocl/2016014

44. Hajib A, Harhar H, Gharby S, Nounah I, Matthäus B, Guillaume D, et al. Is geographic origin a good marker for cumin seed oil (Cuminum cyminum L.)? Riv. Ital Sostanze Gr. (2018) 3:155-9.

45. Taoufik F, Zine S, El Hadek M, Idrissi Hassani LM, Gharby S, Harhar H, et al. Oil content and main constituents of cactus seed oils opuntia ficus indica of different origin in Morocco. Mediter J Nutr Metab. (2015) 8:8592. doi: 10.3233/MNM-150036

46. Gharby S, Guillaume D, Elibrahimi M, Charrouf Z. Physico-chemical properties and sensory analysis of deodorized argan oil. ACS Food Sci Technol. (2021) 1:275-81. doi: 10.1021/acsfoodscitech.0c00107

47. Charrouf Z, Guillaume D. Argan oil: occurrence, composition and impact on human health. Eur J Lip Sci Technol. (2008) 110:6326. doi: $10.1002 /$ ejlt.200700220

48. Mohammed F, Guillaume D, Abdulwali N, Zabara B, Bchitou R. Tin content is a possible marker to discriminate argan oil against olive, sesame, mustard, corn, peanut, and sunflower oils. Eur J Lip Sci Technol. (2019) 121:1800180. doi: 10.1002/ejlt.201800180

49. Khallouki F, Younos C, Soulimani R, Oster T, Charrouf Z, Spiegelhalder B, et al. Consumption of argan oil (Morocco) with its unique profile of fatty acids, tocopherols, squalene, sterols and phenolic compounds should confer valuable cancer chemopreventive effects. Eur J Cancer Preven. (2003) 12. doi: 10.1097/00008469-200302000-00011

50. Khallouki F, Mannina L, Viel S, Owen RW. Thermal stability and long- chain fatty acid positional distribution on glycerol of argan oil. Food Chem. (2008) 110:57-61. doi: 10.1016/j.foodchem.2008.01.055

51. Harhar H, Gharby S, Guillaume D, Bouzoubaa Z, Kartah B, Charrouf $Z$. Influence of argan fruit peel on the quality and oxidative stability of argan oil after prolonged storage. Emir J Food Agr. (2015) 27. doi: $10.9755 /$ ejfa.2015.04.040

52. Hajib A, Nounah I, Harhar H, Gharby S, Kartah B, Matthäus B, et al. Oil content, lipid profiling and oxidative stability of 'sefri' Moroccan pomegranate (Punica granatum L.) seed oil. OCL. (2021) 28:5. doi: 10.1051/ocl/2020069

53. Matthäus B, Brühl L. Quality parameters for the evaluation of cold-pressed edible argan oil. J Fur Verbrauch Lebens. (2015) 10:143-54. doi: 10.1007/s00003-014-0922-8

54. El Monfalouti H, Charrouf Z, Belviso S, Ghirardello D, Scursatone B, Guillaume D, et al. Analysis and antioxidant capacity of the phenolic compounds from argan fruit (Argania spinosa (L.) skeels). Eur J Lip Sci Technol. (2012) 114:446-52. doi: 10.1002/ejlt.201100209

55. El Monfalouti H, Charrouf Z, Giordano M, Guillaume D, Kartah B, Harhar $\mathrm{H}$, et al. Volatile compound formation during argan kernel roasting. Nat Prod Comm. (2013) 8:33-6. doi: 10.1177/1934578X1300800108

56. Charrouf Z, El Hamchi H, Mallia S, Licitra G, Guillaume D. Influence of roasting and seed collection on argan oil odorant composition. Nat Prod Comm. (2006) 1. doi: 10.1177/1934578X0600100511

57. Gracka A, Majcher M, Kludská E, Hradecký J, Hajšlová J, Jeleń HH. Storage-induced changes in volatile compounds in argan oils obtained from raw and roasted kernels. J Amer Oil Chem Soc. (2018) 95:147585. doi: $10.1002 /$ aocs. 12148

58. Ennoukh FE, Bchitou R, Mohammed F, Guillaume D, Harhar H, Bouhaouss A. Study of the effects of extraction methods on argan oil 
quality through its metal content. Indus Crops Prod. (2017) 109:1824. doi: 10.1016/j.indcrop.2017.08.039

59. Harhar H, Gharby S, Kartah B, El Monfalouti H. Long argan fruit drying time is detrimental for argan oil quality. Nat Prod Communi. (2010) 5:18013. doi: $10.1177 / 1934578 X 1000501122$

60. Gharby S, Harhar H, Guillaume D, Haddad A, Matthäus B, Charrouf Z. Oxidative stability of edible argan oil: a two-year study. LWT Food Sci Technol. (2011) 44:1-8. doi: 10.1016/j.lwt.2010.07.003

61. Zaanoun I, Gharby S, Bakass I, Ait Addi EH, Ait Ichou I. Kinetic parameter determination of roasted and unroasted argan oil oxidation under rancimat test conditions. Grasas y Aceites. (2014) 65:e033. doi: 10.3989/gya. 122713

62. Choe E, Min DB. Mechanisms and factors for edible oil oxidation. Compr Rev Food Sci Food Saf. (2006) 5:169-86. doi: 10.1111/j.1541-4337.2006.00009.x,

63. Gharby S, Harhar H, Bouzoubaâ Z, Elmadani N, Charrouf Z. The effect of storage conditions and roasting kernels on extra virgin argan oil quality. $J$ Mater Environ Sci. (2015) 6:254-63.

64. Gharby S, Hajib A, Ibourki M, Sakar EH, Nounah I, Moudden HEL, et al. Induced changes in olive oil subjected to various chemical refining steps: a comparative study of quality indices, fatty acids, bioactive minor components, and oxidation stability kinetic parameters. Chem Data Collec. (2021) 33:100702. doi: 10.1016/j.cdc.2021. 100702

65. Boukyoud Z, Ibourki M, Gharby S, Sakar EH, Bijla L, Atifi H, et al. Can the water quality influence the chemical composition, sensory properties, and oxidative stability of traditionally extracted argan oil? Mediter J Nut Metab. (2021) 14:383-99. doi: 10.3233/MNM-210005

66. Kharbach M, Heyden Y, Marmouzi I, Barra I, Cherrah Y, Bouklouze A, et al. Fatty-acid profiling vs. UV-visible fingerprints for geographical classification of Moroccan argan oils. Food Cntr. (2019) 95:95-105. doi: 10.1016/j.foodcont.2018.07.046

67. Guillén MD, Cabo N, Ibargoitia ML, Ruiz A. Study of both sunflower oil and its headspace throughout the oxidation process. Occurrence in the headspace of toxic oxygenated aldehydes. J Agri Food Chem. (2005) 53:1093101. doi: $10.1021 /$ jf0489062

68. Gharby S, Harhar H, Roudani A, Chafchaouni I, Charrouf Z. Stability oxidative from cosmetic and alimentary argan oil of thermal treatments. Inter J Pharm Sci Inv. (2013) 2:41-6.

69. Gharby S, Harhar H, Guillaume D, Kartah B, Chafchaouni I, Bouzobaa Z, et al. Oxidative stability of cosmetic argan oil: a one-year study. J Cosmet Sci. (2014) 65:81-7.

70. Gharby S, Harhar H, Guillaume D, Haddad A, Charrouf Z. The origin of virgin argan oil's high oxidative stability unraveled. Nat Prod Comm. (2012) 7. doi: $10.1177 / 1934578 X 1200700520$

71. Kharbach M, Marmouzi I, Kamal R, Yu H, Barra I, Cherrah Y, et al. Extra virgin argan oils' shelf-life monitoring and prediction based on chemical properties or FTIR fingerprints and chemometrics. Food Contr. (2021) 121:107607. doi: 10.1016/j.foodcont.2020.107607

72. Miklavčič MB, Taous F, Valenčič V, Elghali T, Podgornik M, Strojnik L, et al. Fatty acid composition of cosmetic argan oil: provenience and authenticity. Criteria Molec. (2020) 25:4080. doi: 10.3390/molecules 25184080

73. Rueda A, Samaniego-Sánchez C, Olalla M, Giménez R, Cabrera-Vique C, Seiquer I, et al. Combination of analytical and chemometric methods as a useful tool for the characterization of extra virgin argan oil and other edible virgin oils. Role of polyphenols and tocopherols. J AOAC Inter. (2016) 99:489-94. doi: 10.5740/jaoacint.15-0121

74. Ourrach I, Rada M, Pérez-Camino MC, Benaissa M, Guinda Á. Detection of argan oil adulterated with vegetable oils: new markers. Grasas y Aceites. (2012) 63:355-64. doi: 10.3989/gya.047212

75. Zougagh M, Salghi R, Dhair S, Rios A. Nanoparticle-based assay for the detection of virgin argan oil adulteration and its rapid quality evaluation. Anal Bioanal Chem. (2011) 399:2395-405. doi: 10.1007/s00216-010-4628-1

76. Salghi R, Armbruster W, Schwack W. Detection of argan oil adulteration with vegetable oils by high-performance liquid chromatography-evaporative light scattering detection. Food Chem. (2014) 153:387-92. doi: 10.1016/j.foodchem.2013.12.084

77. Gonzálvez A, Armenta S, de la Guardia M. Adulteration detection of argan oil by inductively coupled plasma optical emission spectrometry. Food Chem. (2010) 121:878-86. doi: 10.1016/j.foodchem.2009.11.091

78. El Orche A, Elhamdaoui O, Cheikh A, Zoukeni B, El Karbane M, Mbarki $\mathrm{M}$, et al. Comparative study of three fingerprint analytical approaches based on spectroscopic sensors and chemometrics for the detection and quantification of argan oil adulteration. J Sci Food Agri. (2022) 102:95104. doi: $10.1002 /$ jsfa. 11335

Conflict of Interest: The authors declare that the research was conducted in the absence of any commercial or financial relationships that could be construed as a potential conflict of interest.

Publisher's Note: All claims expressed in this article are solely those of the authors and do not necessarily represent those of their affiliated organizations, or those of the publisher, the editors and the reviewers. Any product that may be evaluated in this article, or claim that may be made by its manufacturer, is not guaranteed or endorsed by the publisher.

Copyright $\odot 2022$ Gharby and Charrouf. This is an open-access article distributed under the terms of the Creative Commons Attribution License (CC BY). The use, distribution or reproduction in other forums is permitted, provided the original author(s) and the copyright owner(s) are credited and that the original publication in this journal is cited, in accordance with accepted academic practice. No use, distribution or reproduction is permitted which does not comply with these terms. 